\title{
Improving L2 Macro-Structural Processing in Students with Elementary or Intermediate English Proficiency Levels: an Instructional Approach Focused on Global Coherence in Reading Comprehension of Science Texts
}

\author{
Ángela Gómez, Anna Devís, And Vicente SAnjosé \\ University of Valencia, Spain
}

Received: 19 April 2012 / Accepted: 10 October 2012

ISSN: $1697-7467$

\begin{abstract}
Previous studies have shown that students have difficulties building the macro-structure from expository texts in English (as L2). The usual cause pointed out is a lack of language proficiency. Thus, instructional methods have focused on providing students with the necessary vocabulary and grammar knowledge. This study proposes and validates an instructional approach which improves students' L2 processing on the macro-structural level, focusing on reading strategies rather than on vocabulary or grammar. Comprehension monitoring on the macro-structural level was improved by performing instructional tasks devoted to establish global coherence. As a consequence, students' reading comprehension also improved.
\end{abstract}

Keywords: TEFL; Instructional procedure; Comprehension Monitoring; Macrostructure; Science Texts.

Mejorando el procesamiento macro-estructural en L2 en estudiantes con niveles de inglés elementales o intermedios: un procedimiento instruccional centrado en la coherencia global en la comprensión lectora de textos científicos

RESUMEN: Estudios anteriores han mostrado que los estudiantes tienen dificultades para construir la macroestructura de textos expositivos en inglés (como L2). La causa usualmente aducida es una falta de dominio lingüístico. Por tanto, los métodos instruccionales se han centrado en proporcionar a los estudiantes vocabulario y conocimiento gramatical. Este estudio propone y valida un procedimiento instruccional que mejora el procesamiento macroestructural en L2, centrándose en estrategias de lectura en vez de en vocabulario o gramática. El control de la comprensión macroestructural mejoró gracias a tareas de establecimiento de la coherencia global. Como consecuencia, la comprensión lectora de los estudiantes también mejoró.

Palabras clave: Enseñanza del Inglés como Lengua Extranjera; Procedimiento Instruccional; Control de la Comprensión; Macro-estructura; Textos Científicos. 


\section{INTRODUCTION}

Previous studies have analysed the level of comprehension shown by university students when they read expository texts about science topics in English (as L2), and have related it with their comprehension monitoring skills (Block, 1992; Sanjosé, Solaz \& Gómez, 2011). Results showed that students with elementary or intermediate levels of English poorly monitored textual global coherence in L2 compared to the one in their mother tongue. Students' proficiency in L2 was expected to explain their monitoring performance, but that factor only explained a small part of the variance (only $17 \%$ in the study by Gómez, Devís \& Sanjosé, 2013).

The simplest hypothesis to explain students' monitoring difficulties on the text macrostructural level when they read in English is to suppose that most students do not construct the text macro-structure properly. This hypothesis received support in a previous study (Gómez, Devís \& Sanjosé, 2012) aimed to develop students' comprehension monitoring of macro-ideas using summarization tasks to teach students to grasp text main ideas. Despite the success of that exploratory study some aspects have to be addressed: 1) First, measures of reading comprehension should be taken into account, apart from the ones of comprehension monitoring. 2) Different text structures have to be considered to make the instructional procedure more general and functional. 3) Specific instructional work to establish global coherence among text main ideas seems to be desirable to help students to build a better Textbase mental representation (with the micro and macro-structural levels) and, thus to improve their reading comprehension of text main ideas.

This study is specifically addressed to the aforementioned three points extending a previous instructional approach with the aim of changing the way students with low or intermediate English proficiency levels process expository texts, very usual in academic and labour contexts.

\section{TheORETICAL FOUNDATIONS}

Segalowitz, (2000), Walczyk, (2000) and Koda, (1990, 1996) explained that non-bilingual students having low or intermediate language proficiency tend to process English texts (in L2) at 'word' or local level in a 'bottom-up' processing, and not at a global level (Kozminsky $\&$ Graetz, 1986). Translation into their native language is the main reading strategy used by these students (Gómez, Solaz \& Sanjosé, 2012). Therefore, their working memory could be loaded by many poorly-elaborated chunks, i.e., L2 words (or perhaps clauses) so not having enough cognitive resources to build macro-ideas (Walter, 2004, 2007; Yamashita, 2002; Tsai et al., 2010) or to connect them to build the macro-structure.

Stanley (1984) and Block (1992) found similar problems and recommended a shift in TEFL towards new approaches focusing on global or semantic processing of text information. The challenge is how to teach students to focus on macro-structural processing when they read in English.

Of course, being aware of text macro-ideas is the first step to macro-structure construction, but it is not enough. Certain instructional tasks, such as summarization, resulted very efficient to help students grasp the text main ideas. Once main ideas have been grasped, 
they have to be connected to establish the so called 'global coherence'. i.e. the semantic relationship among main ideas (or among macro-ideas) in the text.

To connect macro-ideas they have to be processed together in the working memory. However, science texts are so complex that main ideas can be separated by many other secondary ideas. In this case the considered main ideas are not processed together in the working memory because of its limited capacity, no matter the English proficiency. In educational text design, re-stating ideas previously read in the text is an efficient way to increase the number of connections among ideas within a text. Re-stating ideas refreshes the memory and aids the reader in her/his understanding (Kintsch, \& van Dijk, 1978; Britton, Van Dusen, Glynn, \& Hemphill, 1990). This strategy used to improve educational texts can be transferred to other instructional procedures developed in the classroom. Re-stating an important idea in a text is similar to re-stating the same idea verbally or to suggest students to re-process some specific parts of a text containing the idea.

The level of success in the construction of the text macro-structure can be assessed in several ways. First, the subjects' ability to grasp the main ideas of a given text can be measured by means of summary elaboration. Summaries have quite often been used as assessing instruments as well as instructional tasks (Kim, 2001; Cohen, 1994; Johns, 1986). Second, global coherence can be assessed by means of "error detection tasks" (Baker, 1985; Winograd \& Johnston, 1982; Baker \& Anderson, 1982). These tasks consist in embedding errors in important ideas to make them inconsistent or incoherent and asking readers to assess the comprehensibility of the resulting text. If readers properly construct the text macro-structure they have to detect such incoherent ideas because the embedded errors violate global coherence. Subjects' comprehension monitoring is implied in this process. 'Comprehension monitoring' is the metacognitive ability of a reader to be aware, while reading, whether a text is making sense or not (Brown, Bransford, Ferrara \& Campione, 1983; Flavell, 1981). It is related to self-regulation which strongly affects learning (Zimerman, 1990; Corno, 1986). Detecting embedded errors has been previously used to study comprehension monitoring in L2 reading (Block, 1986, 1992; Morrison, 2004; Han \& Stevenson, 2008).

\subsection{Goals}

Our main goal was to improve students' processing of macro-ideas in reading-forunderstanding tasks, as it is the case of understanding science texts. We studied students' text processing by means of their monitoring of global coherence and by their success grasping main ideas and differentiating them from other secondary ideas.

Therefore, being able to properly process text macro-ideas implies the following subgoals:

Sub-goal 1: To grasp the text main ideas and to differentiate them from other secondary ideas. Gómez, Devis \& Sanjosé, (2012) reported significant improvement in comprehension monitoring of macro-ideas when students' task consists in reading and summarizing instead of simply reading and understanding. . Here, we will use the same 'instructional programme" (Sánchez, 1993) to teach students how to grasp main ideas from an expository text. This programme is in line with Kominsky \& Graetz's (1986) recommendation of directing students to process texts at least at paragraph level.

Sub-goal 2: To monitor the meaning of these main ideas in order to produce a cohe- 
rent representation of the whole text, i.e. to establish "global coherence". This is a specific, new purpose not present in previous instructional approaches. To build a suitable Textbase representation of the text grasping main ideas is not enough. It is also necessary to relate them in a coherent manner.

In order to reach these sub-goals, we designed and implemented an instructional procedure based on different tasks with specific purposes. Of course, we expected that reaching the above sub-goals will lead to improvement in reading comprehension as a direct consequence.

\section{3. Меthod}

\subsection{Participants}

Thirty-two male and female Spanish university students participated in this study. They belonged to an intact group at a Teacher Training Faculty from a big city. They were enrolled in English Language for Teachers, a subject taught in the first year of the degree combining language knowledge (on the B1 level) with teaching skills. The instructional tasks proposed were inserted in the usual lessons in order to develop students' reading competence. Students were level-graded in English proficiency with a usual placement test according to the Common European Framework of Reference for Languages (CEFRL; Council of Europe, 2001). The distribution of the sample in these grades was: $10 \%$ in A1-level; $57 \%$ in A2; $23 \%$ in $\mathrm{B} 1$ and $10 \%$ in $\mathrm{B} 2$. Thus, most of the participants were in the elementary (A2) or intermediate (B1) levels.

\subsection{Design}

The instruction was designed with the aim of changing students' level of processing of English texts (from word to semantic or global level) and improving their macro-structural comprehension monitoring. This was a one-group study with a Pretest-Intervention-Posttest structure.

\subsection{Pretest and posttest: materials and measurements}

The following measures were taken both in the pretest and the posttest phase:

Measure 1: Summarization ability. We used summarization to obtain a measure of subjects' ability to grasp main ideas. Grasping main ideas and differentiating them from other secondary ideas -as it has to be done in summarization- is essential to understand the text at macro-structural level.

We prepared two long texts (a page, about 400-500 words) on general science topics (biomass and marijuana) in order to evaluate students' ability to grasp the main ideas of the texts and to elaborate summaries. The texts were of similar reading difficulty (Flesch's score between 40-45) and they had a typical structure of science expository texts (description, cause and consequence). One of these texts was used in the pretest and the other in the posttest. Two different experts elaborated summaries for the two texts. Discrepancies were 
solved by discussion and a final set of main ideas of each text was obtained. This set of main ideas was used to assess students in the pretest and the posttest.

In the pretest and posttest sessions the text and a blank sheet of paper were given to students to write a summary of it. Summaries were asked to be written in Spanish (L1) in order to avoid the influence of writing competence. The tasks were performed in two class sessions and each one took less than $45 \mathrm{~min}$. Several measures were obtained from the summaries:

Variable 1: Quality of the summary: the number of main ideas divided by the total possible number of main ideas + secondary ideas included + extraneous ideas included + wrong ideas included. This index assigns the value " 0 " when a summary does not include any single main idea, and " 1 " when the summary includes only main ideas and all the possible main ideas.

Variable 2: Number of wrong and extraneous ideas. Wrong ideas are those including comprehension and/or translation mistakes. Extraneous ideas are those not present in the text (for example, those coming from the subject's prior knowledge).

Measure 2: Monitoring Global Coherence. In order to measure students' monitoring of global coherence we used the same material described in Gómez, Devís \& Sanjosé (2012) based on the Error Detection Paradigm (Baker, 1985; Winograd \& Johnston, 1982; Baker \& Anderson, 1982). We prepared 4 short texts in English of comparable length (200-245 words), structure, reading difficulty (Flesch's score: 45-60) and similar content (general science topics such as climate change, evolution of species, cloning). Each text had three paragraphs, the last one being a summary containing the macro-ideas of the text. Two macro-structural errors were embedded in this final paragraph so that they contradicted previous textual macro-ideas. Two of these texts were used in the pretest and two in the posttest as a comprehension monitoring measure. In the pretest and posttest sessions, the instructions, an example for practice and the two texts in a counterbalanced order were given to participants. They were asked to evaluate the comprehensibility of the texts and underline any contradictory or non-coherent idea or any unknown word using a particular key code. We expected good comprehenders would detect and underline the contradictions. The variable was:

Variable 3: Total right detections of macro-structural errors. This value ranged from 0-4 because each participant read two texts with two errors embedded in each one.

Measure 3: Answering questions on a text. One of the desired consequences of improving students' macro-structural processing is a better reading comprehension. There are many ways to assess reading comprehension (Keenan, Betjemann \& Olson, 2008) and a classical method is to formulate questions about the text content to be answered by readers. We used materials included in The Comprehension Processes Test (Martínez, Vidal-Abarca, Sellés \& Gilabert, 2008; Fernández-Rivera, 2008, Appendix V). It is a validated test for L1 reading in Spanish. The test consisted in reading two texts and answering ten questions about each text. These questions evaluate particular reading comprehension sub-skills (making anaphoric inferences, building macro-ideas, using the reader's knowledge to make inferences and identifying explicit ideas). In order to avoid students' overload we used one of these texts in the pretest (The Penguin; Flesch's score $=69$ ) and the other in the posttest (The Sioux; Flesch's score= 59). We translated them into English together with the questions involved. A small glossary of some difficult terms was included to help students understand the text. 
Students were given the text with ten comprehension questions. They spent less than $45 \mathrm{~min}$ to answer them. We obtained the next measure:

Variable 3: Total score (0-10 points) in the pretest and also in the posttest.

Two sessions were needed to obtain the measures for the pretest and two for the ones of the posttest. We obtained complete data from twenty-two students but some measures were obtained from all the participants.

\subsection{Instructional Materials}

Several tasks were proposed throughout the instructional sessions. Different materials were needed for each one:

Task 1. Advanced Organizer: There are different levels of reading processing that are necessary to understand texts.

In this introductory task we used the short text about the "Modern-Day Romeo" (Bransford \& Johnson, 1972) in Spanish (L1). It describes a situation with comprehensible single sentences but it is very difficult to establish the global coherence of the text and so building the Situation Model representation is very hard.

Task 2. Related to Sub-goal 1: Grasping text main ideas and differentiating them from other secondary ideas (summarization task).

Summarization tasks have proven to improve comprehension (Thiede \& Anderson, 2003) because they promote self-testing and so better monitoring while reading (Gómez, Devis \& Sanjosé, 2012). We used two expository texts ("Biomass" and "Rainbow") of about 500 words prepared to include at least one main idea per paragraph. The first paragraph described a natural phenomenon and the second one explained their causes. The next paragraphs developed some characteristics or advanced some consequences for humans.

Task 3.- Related to Sub-goal 2: To monitor the meaning of these main ideas in order to produce a coherent representation of the whole text, i.e. to establish "global coherence".

We considered four sub-tasks (detecting an extraneous idea embedded in an extended text; judging the quality of a summary; ordering the paragraphs to re-state the coherence of a text; detecting between-paragraph macro-structural inconsistencies in an extended text) and used different materials for them.

Subtask 3.1: Detecting an extraneous idea embedded in a text. We used a short text prepared for this task ("Edison's life" www.thinkport.org/a4092856-945a-4952-aceb-9f606e84af36. asset) with a standard reading difficulty (245 words; Flesch's score: 67).

Subtask 3.2: Judging the quality of a given summary. We used two short texts (210-220 words) of increasing reading difficulty (Flesch's scores: 61 and 48) about general science topics ("Climate Change" and "Evolution") and asked students to write their own summaries. Next, we gave them two already prepared summaries including errors in main ideas. Students had to judge the quality of those given summaries and explain their criteria.

Subtask 3.3: Ordering paragraphs to re-state the coherence of a text. We translated a short text into English ( 272 words) about the formation of the atmosphere ("Atmosphere") 
in Earth's history from Sánchez's book (1993: 328). It had a sequential structure and it was fairly difficult to read (Flesch's score: 51). Paragraphs were disordered and explicit textual links were deliberately suppressed. In that way students had to focus on the meaning of the paragraphs to re-state textual coherence.

Subtask 3.4: Detecting between-paragraph macro-structural inconsistencies in a text. We translated and modified a text about mammals' adaptation ("Mammals"; 279 words; Flesch's score: 55) from Sanchez's book (1993: 54). It had a causation super-structure. We modified three different paragraphs to introduce wrong ideas. Each wrong macro-idea was inconsistent with important ideas in other paragraphs (see Appendix).

\subsection{Instructional Procedure}

The instructional phase took a total time of six hours and it was developed in four sessions:

Session 1: This session was aimed at making students be aware that different levels of mental representation of a text should be built in order to understand it. Previous studies showed that university students having low or intermediate English proficiency levels exhibit good processing on the word or Surface level in L2 but not on the macro-structural level (Kozminsky \& Graetz, 1986; Koda, 1990, 1996; Gómez et al., 2013). So the first step in the instruction was making students be aware of this fact. We used the text of the ModernDay Romeo (Bransford \& Johnson, 1972) translated into Spanish (L1), and asked students to read it on their own (Task 1; see Instructional Materials sub-section). Then, we asked them about its content. Most of the students were surprised, got angry or laughed because they could not understand the text although it was written in their mother tongue.

After being aware that the text did not make sense because global coherence had been broken down, students were given a picture representing the situation described in the text. We used the model by Kintsch \& van Dijk (1978) to explain them the three proposed mental representations (Surface, Textbase and Situation Model). We emphasized the fact that the three levels were needed to understand the text in their mother tongue. Then, why didn't they do the same in English? Why did they only process word by word or clause by clause? Going beyond these low processing levels would imply grasping the text main ideas and building the global coherence. This session took $60 \mathrm{~min}$.

Session 2: The aim of this session was helping students identify the text main ideas and distinguish them from other less important ideas (see Task 2 in Instructional Materials sub-section). An outline illustrating the main steps to write a good summary was provided to students. It was an adaptation to L2 of Sánchez's (1993) programme of reading comprehension instruction. This programme had given good learning results in a previous study (Gómez, Devís \& Sanjosé, 2012). Students applied the summarization procedure to two texts. Special emphasis was put on working and understanding paragraph by paragraph instead of isolated ideas or single words. In order to control students' progress we asked readers to circle those words they considered 'essential' to understand the paragraph. In the first summary, some students were reluctant to continue reading without knowing the meaning of the words they had circled. They stopped and felt overwhelmed. They were processing 
the text on the word level. The teacher acted in two ways: first, the three levels of mental representation of a text were reviewed again; next, she made them notice that they could actually understand the main idea of the whole paragraph without knowing the meaning of every word. She encouraged students to go on reading. After the instructional work developed in the first text, students had better performance in the second one. Leaving apart vocabulary problems, students did not have great difficulties in identifying main ideas and when discrepancies came up they were solved by discussion. Thus, students self-perceived that they had been able to understand the 'essential content' of the texts despite of the fact that they did not know every single word. Therefore, they could identify the main ideas and write acceptable summaries. They might be starting to change their focus of processing texts from the word to the semantic level.

The session took around $120 \mathrm{~min}$.

Session 3: In this session students went on working on identifying the text main ideas but they were also instructed in establishing the global coherence of a text. The first subtask consisted in detecting an extraneous idea embedded in a text (Subtask 3.1 in the Instructional Materials sub-section). They read the first two paragraphs (out of 4) of the text about Edison's life with the aim of learning more about him. They were not warned that the second paragraph contained the embedded extraneous idea but we expected good comprehenders to detect it. After reading the text the instructor asked them what they had learnt about Edison and realized that only a pair of them had noticed the inconsistency. So they were asked to read the two next paragraphs of the text with two goals in mind: learning more about Edison and establishing coherence between the ideas of the text. Students expected to find more inconsistencies and so they processed the text in a different way. The remaining paragraphs were free of inconsistencies and after reading them, students found these ideas were coherent. We made them think about the way they had read the two first paragraphs and compare it to the way they had read the two final ones. They were aware that they had paid more attention and checked their comprehension more times when reading the second part. Students were shocked because they thought they always read in the same way!

The instructor told them this should be the way good readers read and understand texts.

To perform the second subtask students were provided with two short texts. They had to write a short final paragraph containing the macro-ideas of the text. After reading some of these summaries aloud, the instructor gave them an already prepared summary (Subtask 3.2 in the Instructional Materials sub-section). Students were not warned that it contained two macro-structural errors contradicting previous text macro-ideas. Because of previous instructional work, we expected them to detect the errors but only a few students actually did it. We made students reflect on the fact that although tasks may be different, their reading goals should always be the same: grasping the main ideas and establishing the global coherence of the text.

The session took around $120 \mathrm{~min}$.

Session 4: As in the previous session, students practiced grasping main ideas and establishing the texts global coherence. Two subtasks were proposed for this session. The first task consisted in putting in order some paragraphs to build a coherent text (subtask 3.3 
in the Instructional Materials sub-section). Some students thought this was going to be an easy task, as they were used to this kind of activities. But ordering the paragraphs did not result in an automatic task and it demanded students some cognitive effort because explicit textual links had been suppressed. In that way students were forced not only to understand the main ideas of the whole paragraphs (understanding global meaning) but also to establish the relationships among them to re-state coherence.

For the second task they had to imagine they were actual teachers (remember that our students were pre-service Primary and Infant school teachers) and they had to judge the comprehensibility of a text. They could modify and re-write whatever they thought it was not comprehensible enough (Subtask 3.4 in Instructional Materials sub-section). They were not warned that three paragraphs of the text contained embedded wrong macro-ideas which were inconsistent with some important ideas from other paragraphs. We expected students would detect these inconsistencies when trying to build the global coherence of the text. However, this did not happen. Students declared the text was comprehensible enough and they would not modify or re-write anything. Then, the instructor followed the same procedure as in session 1 and worked on the text paragraph by paragraph, grasping the main ideas and establishing coherence relationships among them. Despite this, only a few students detected the inconsistencies. Some students started to cry when they realized that despite the previous instructional work and warnings, they had failed to process the text in a suitable way.

Again, the instructor reminded students that the task may vary but they should always read with two reading goals in mind: grasping the main ideas and establishing the global coherence of a text.

This session took around $60 \mathrm{~min}$.

We expected this instructional work to produce a change of students' reading processing from a low (word or single ideas) to a high level (macro-structural level).

Instruction did not explicitly deal with vocabulary, grammar or exercises specifically addressed to increase students' English proficiency level. Instead, it was addressed to optimize actual proficiency in reading-for-understanding tasks. Instruction did not include readand-answer tasks so any improvement in this measure should be an indirect consequence of other variables.

\section{Results AND Discussion}

Participants' English proficiency level was considered as a possible predictor when we studied learning effects because it could interact with instructional factors.

\subsection{Pretest}

Table 1 shows the mean values (and standard deviations) obtained in the considered variables for our measures: Summarization ability, Monitoring global coherence and Question answering. For the first measure we considered two different variables: the quality of the summary and the number of wrong and extraneous ideas, i.e. ideas included in the summary but which are not present in the text. 
Table 1. Pretest: Mean (SD) for the variables considered in this study

\begin{tabular}{llc}
\hline Pretest Measures & Variables & Mean value $(\mathrm{SD})$ \\
\hline 1.-SumAbil & 1.-Quality of the Summary $(\max =1)$ & $.28(\mathrm{SD}=.13)$ \\
& 2.-Wrong and extraneous ideas & $4.33(\mathrm{SD}=2.48)$ \\
2.-MonGloCoh & 3.-Detected macro-errors $(\max =4)$ & $1.40(\mathrm{SD}=1.13)$ \\
3.-AnsQuest & 4.-Score $(\max =10)$ & $6.71(\mathrm{SD}=1.77)$ \\
\hline
\end{tabular}

Students elaborated summaries with a low quality index and showed a low monitoring of global coherence (comprehension monitoring of macro-ideas) replicating previous studies (Cordero-Ponce, 2000). The pretest summaries included a considerable number of wrong and extraneous ideas. However, students did not perform the answering questions test so bad (they failed to answer 3-4 questions out of 10); probably, questions focused their attention to concrete text segments and this improved their comprehension.

In order to study the relationship among these variables, we computed the corresponding Pearson's correlations (all the measures were normally distributed). Table 2 shows these correlations. The English proficiency level has also been included.

Table 2. Pretest: Pearson's correlations among the variables considered in this study

\begin{tabular}{lcccc}
\hline & $\begin{array}{c}\text { 2.-Wrong } \\
\text { \& Extra }\end{array}$ & $\begin{array}{c}\text { 3.-Detected } \\
\text { macro-errors }\end{array}$ & $\begin{array}{c}\text { 4.-Question } \\
\text { Answer }\end{array}$ & $\begin{array}{c}\text { 5.-English } \\
\text { Proficiency }\end{array}$ \\
\hline 1.-Quality Summary & $-.66^{* *}$ & .08 & $.55^{* *}$ & $.39 *$ \\
2.-Wrong \& Extraneous & -- & -.33 & $-.38^{*}$ & $-.35 *$ \\
3.-Detected macro-errors & -- & -- & $.44 *$ & $.61 * *$ \\
4.-Question answer & -- & -- & -- & $.68 * *$ \\
\hline
\end{tabular}

$(*): \mathrm{p}<.05 ;(* *): \mathrm{p}<.01$.

Correlations followed an expected trend: the English proficiency level was significantly correlated with all the pretest measures. In addition, the reading comprehension score was significantly correlated with the comprehension monitoring measure and with the summary measure. The summary quality index was inversely correlated with the number of wrong and extraneous ideas.

\subsection{Posttest}

After the instructional sessions we took the same measures again. Table 3 shows the mean values $(\mathrm{SD})$. 
Table 3. Posttest: Mean (SD) for the variables considered in this study

\begin{tabular}{lll}
\hline \multicolumn{1}{c}{ Posttest Measures } & \multicolumn{1}{c}{ Variables } & \multicolumn{1}{c}{ Mean value (SD) } \\
\hline 1.-SumAbil & 1.-Quality of the Summary $(\max =1)$ & $.44(\mathrm{SD}=.14)$ \\
& 2.-Wrong and extraneous ideas & $1.09(\mathrm{SD}=1.57)$ \\
2.-MonGloCoh & 3.-Detected macro-errors $(\max =4)$ & $2.66(\mathrm{SD}=1.29)$ \\
3.-AnsQuest & 4.-Score $(\max =10)$ & $7.52(\mathrm{SD}=1.83)$ \\
\hline
\end{tabular}

The posttest Quality of the summary variable was not significantly correlated to the corresponding pretest Quality of the summary variable but the signification was near the standard limit $(r=.30 ; \mathrm{p}=.09)$. The Global coherence monitoring measure in the posttest was significantly correlated to the corresponding pretest measure $(r=.43 ; p=.033)$, and the same happened for the pretest/posttest number of Wrong and extraneous ideas $(r=.40 ; p=$ $.025)$ and the pretest/posttest Question answering measure for reading comprehension ( $\mathrm{r}=$ $.50 ; \mathrm{p}=.006)$.

Pearson's correlations among the posttest measures and the English proficiency level are included in Table 4.

Table 4.- Posttest: Pearson's correlations among the variables considered in this study

\begin{tabular}{lllll}
\hline & $\begin{array}{l}\text { 2.-Wrong } \\
\text { \& Extra }\end{array}$ & $\begin{array}{l}\text { 3.-Detected } \\
\text { macro-errors }\end{array}$ & $\begin{array}{l}\text { 4.-Question } \\
\text { Answer }\end{array}$ & $\begin{array}{l}\text { 5.-English } \\
\text { Proficiency }\end{array}$ \\
\hline 1.-Quality Summary & $-.50 * *$ & $.45 *$ & .34 & .25 \\
2.-Wrong \& Extraneous & -- & -.19 & -.18 & -.24 \\
3.-Detected macro-errors & -- & -- & $.66 * *$ & $.52 * *$ \\
4.-Question answer & -- & -- & -- & $.60 * *$ \\
\hline
\end{tabular}

(*): $p<.05 ;(* *): p<.01$.

In the posttest, the English proficiency level was only significantly correlated with the comprehension monitoring and the reading comprehension measures. The reading comprehension score was significantly correlated with the comprehension monitoring measure only. The summary quality index was inversely correlated with the number of wrong and extraneous ideas again. Comprehension monitoring was significantly correlated with the reading comprehension score and also with the summary quality measure.

\subsection{Pretest-Posttest differences}

The effects coming from the experimental instruction can be assessed by the changes produced in the considered variables. As these variables fitted normal distributions, we used parametric test in this study. We performed different $2 \mathrm{X} 4$ repeated measures 
ANOVA, taking the pretest/posttest as the within-subjects factor, and the English proficiency level (A1/ A2/ B1/ B2) as the between-subjects factor.

The ability to elaborate good summaries improved significantly. The English proficiency level did not produce any significant effect $(F(3,28)=1.140 ; p=.350)$ and there was no interaction effect $(\mathrm{F}<1)$. Thus, we excluded it from the analyses and retained the pretest/posttest factor only. There were significant pretest/posttest differences with a large effect size in the Quality of the summary measure $(F(1,31)=20.553 ; p<.001$; $\left.\eta^{2}=.40\right)$.

Regarding the other summary measure, i.e., the number of wrong and extraneous ideas in the summaries, they diminished significantly $\left(F(1,28)=27.197 ; p<.001 ; \eta^{2}=\right.$ .49) without a main effect from the English proficiency level $(F(3,28)=1.127 ; p=.355)$ or an interaction effect $(\mathrm{F}<1)$.

The variable 'Monitoring the global coherence' also improved significantly $(\mathrm{t}(24)=$ -5.421; $\mathrm{p}<.001)$. When English proficiency was also considered, this between-subjects factor was significant $\left(\mathrm{F}(3,21)=4.333 ; \mathrm{p}=.016 ; \eta^{2}=.38\right)$ but pretest/posttest differences (the within-subject factor) did not vanish but remained with a large effect size $(\mathrm{F}(1,21)=$ $\left.10.758 ; p=.004 ; \eta^{2}=.34\right)$. Therefore, the instructional procedure was very effective.

Figure 1 shows the dependency of the number of detected macro-inconsistences in the pretest and in the posttest, with the English proficiency level.

There was not significant interaction effect $(\mathrm{F}<1)$ between the within and the between factors.

In the Question answering measure, associated to reading comprehension, the pretest/posttest differences were significant and the effect size was moderate-to-large $\left(\mathrm{F}(1,28)=5.008 ; \mathrm{p}=.033 ; \eta^{2}=.15\right)$.

The possible changes in this reading comprehension score from the pretest to the posttest were supposed to be caused by subjects' reading processing improvement as a consequence of the instructional treatment. Table 5 shows that in the posttest, this variable was significantly correlated to the English proficiency and to the number of detected macro-inconsistences (global coherence monitoring) as expected. 


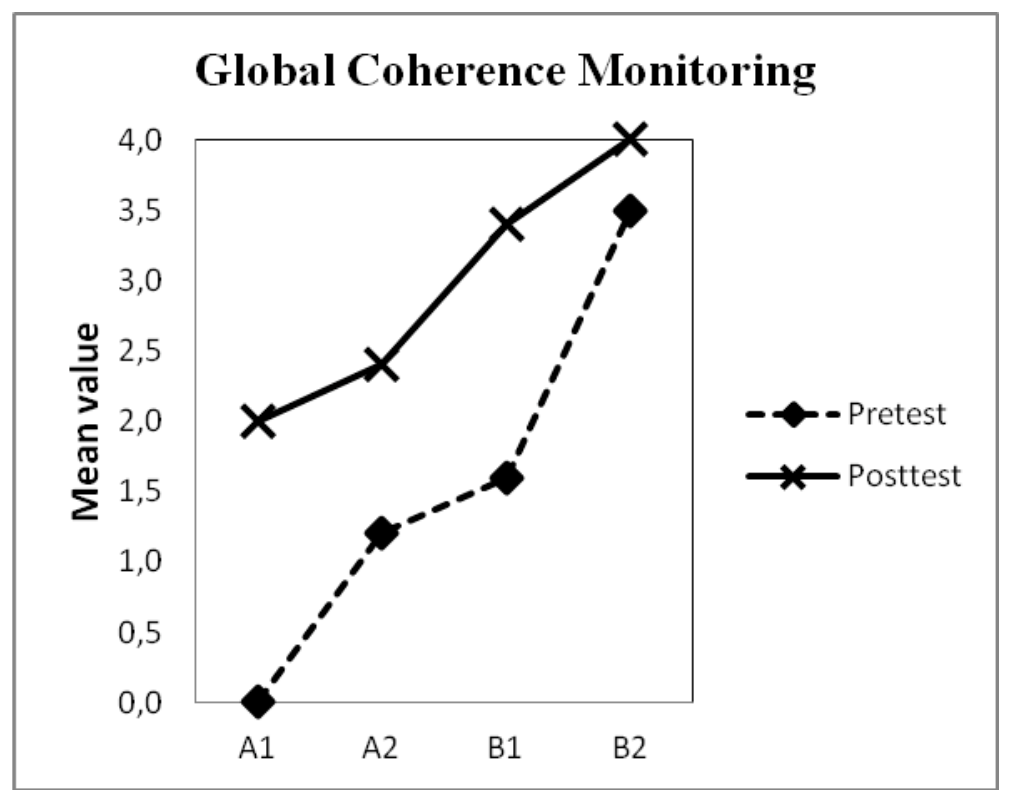

Figure 1. Mean values for the number of the correctly detected embedded macro-inconsistencies in the English texts.

\section{Conclusions}

Long time ago, Stanley (1984) proposed that TEFL should focus on global processing of text information. In this study we followed this suggestion and implemented an instructional procedure oriented to help university students to construct English (L2) text macro-structure. This instruction was based on two main points: (a) to grasp the text macro-ideas; (b) to establish coherence relations among text ideas.

Previous diagnostic studies (Gómez, Devís \& Sanjosé, 2013) showed that most students process L2 texts word by word or clause by clause. Thus, our instructional procedure not only included instructional tasks to change the students' processing level by means of summarization tasks, but also included instructional tasks to link main ideas in a coherent way. Re-stating important ideas verbally or suggesting students to re-process some important text segments was the underlining main strategy used in those latter tasks.

Specific procedures devoted to improve students' summarization ability were associated to improvements in processing text main ideas (Gómez, Devís \& Sanjosé, 2012), replicating previous studies in other contexts (Cordero-Ponce, 2000). Therefore, our instructional approach included such procedures but added new ones addressed to teach students, having low or intermediate English proficiency levels, to establish global coherence among the textual main ideas (so going beyond simply grasping the main ideas). We expected that working on establishing global coherence would make students be aware of the semantic relations 
among main ideas and so would improve their ability of monitoring their understanding of important ideas when reading. If comprehension monitoring of main ideas improves, reading comprehension should improve as well.

To assess our instructional approach we considered variables associated to text processing: summarization quality, monitoring global coherence and question answering. Results showed significant positive changes in all these measures.

First, the quality of the summaries elaborated by students improved significantly without any effect from the English proficiency, so the 'instructional programme' (Sánchez, 1993) to teach students to grasp text main ideas was effective even for participants having elementary English proficiency levels. Second, students' significantly improved their monitoring of global coherence. The effect of the English proficiency was significant in the pretest/ posttest differences although the instructional effect remained significant with a large effect size. This result indicates that our instructional approach was very effective in improving students' comprehension monitoring on the macro-structural level of text processing. Finally, reading comprehension also improved significantly as measured by a question answering task. As our instructional procedure did not include any question answering task, this effect was indirectly caused by the improvement in other processing variables.

Summing up, our instructional approach seemed to be suitable to change students' text processing from low levels (word, clause) to higher levels (macro-ideas) making possible macro-structure construction and also comprehension monitoring at this level, no matter their English proficiency level. Different textual materials were prepared and used in the instructional procedure and they seem to be suitable for our purposes.

\section{REFERENCES}

Baker, L. and Anderson, R. I. (1982). "Effects of Inconsistent Information on Text Processing: Evidence for Comprehension Monitoring", in Reading ResearchQuarterly, 17: 281-294.

Baker, L. (1985). "How do we Know When we don't Understand? Standards for Evaluating Text Comprehension", in D.L. Forrest-Pressley. G. E. Mackinnon. and T.G. Waller (Eds.), Metacognition.cognition and human performance. New York: Academic Press, 155-205.

Block, E. (1986). "The Comprehension Strategies of Second Language Readers", in TESOL Quarterly, 20, 3: 463-494.

Block, E. (1992). "See How They Read: Comprehension Monitoring of L1 and L2 Readers", in TESOL Quarterly, 26, 2: 319-343.

Bransford, J.D. and Johnson, M.K. (1972). "Contextual Prerequisites for Understanding: Some Investigations of Comprehension and Recall", in Journal of Verbal Learning and Verbal Behaviour, 11, 6: 717-726.

Britton, B. K., Van Dusen, L., Glynn S. M., and Hemphill, D. (1990). "The Impact of Inferences on Instructional Text", in A. C. Graesser and G. H. Bower (Eds.), The Psychology of Learning and Motivation. San Diego, CA: Academic Press, 25:53-70.

Brown, A., R. Bransford, R. Ferrara. and Campione, J. (1983). "Learning, Remembering, and Understanding", in P. Mussen (Ed), Handbook of Child Psychology: Cognitive development. New York, John Wiley and Sons.

Cohen, A.D. (1994). "English for Academic Purposes in Brazil: The Use of Summary Tasks", in C. Hill and K. Parry (eds.), From Testing to Assessment: English as an International Language. London: Longman, 174-202. 
Cordero-Ponce, W.L. (2000). "Summarization Instruction: Effects on Foreign Language Comprehension and Summarization of Expository Texts", in Reading Research and Instruction, 39, 4: 329-350.

Corno, L. (1986). "The Metacognitive Control Components of Self-regulated Learning", in ContemporaryEducationalPsychology, 11: 333-346.

Council of Europe (2001). Common European Framework of Reference for Languages: Learning. Teaching. Assessment. Cambridge (U.K.): Cambridge University Press.

Fernández-Rivera, J.J. (2008). "Análisis de los Procesos de Búsqueda de Información Textual Orientada a la Resolución de Cuestiones y su Influencia en la Comprensión de las Ciencias: el Caso de la Evolución", Dissertation (Appendix V: 344-351). Servicio de Publicaciones de la Universidad de Valencia.

Flavell, J.H. (1981). "Cognitive monitoring”, in W. P. Dickson (Ed.), Children's Oral Communication Skills.New York: AcademicPress, 35-60.

Gómez, A., Devís, A. and Sanjosé, V. (2012). "Effects of Summarization Tasks on Comprehension Monitoring of Science Texts in University Students with Elementary or Intermediate English Proficiency", in Porta Linguarum. 18: 161-176.

Gómez,A., Devís, A. and Sanjosé, V. (2013). "Control de la Comprensión Macro-estructural Durante la Lectura de Textos Científicos en lengua Extranjera: ¿Algo más que Dominio del Idioma?", in Revista Signos, 46, 81: 56-81.

Gómez, A., Solaz, J.J. and Sanjosé, V. (2012). "Competencia en Lengua Inglesa de Estudiantes Universitarios Españoles en el Contexto del EEES: Nivel de Dominio Lingüístico, Estrategias Metacognitivas y Hábitos Lectores", in Revista de Educación, in press. Available in: http://www.revistaeducacion.mec.es/doi/363_175.pdf.

Han, F. and Stevenson, M. (2008). "Comprehension Monitoring in First and Foreign Language Reading", in University of Sydney Papers in TESOL, 3: 73-110.

Johns, A.M. (1986). "Coherence and Academic Writing: Some Definitions and Suggestions for Teaching", in TESOL Quarterly, 20, 2: 247-265.

Keenan, J.M., Betjemann, R.S. and Olson, R.K. (2008). "Reading Comprehension Tests Vary in the Skills They Assess: Differential Dependence on Decoding and Oral Comprehension”, in Scientific Studies in Reading, 12, 3: 281-300.

Kim, S.A (2001). "Characteristics of EFL Readers' Summary Writing: A Study with Korean University Students", in Foreign Language Annals, 34, 6: 569-581.

Kintsch, W. and van Dijk, T.A. (1978). "Towards a Model of Text Comprehension and Production", in Psychological Review, 85: 363-394.

Koda, K. (1990). "The use of L1 Reading Strategies in L2 Reading", in Studies in Second Language Acquisition, 12: 393-410.

Koda, K. (1996). "FL Word Recognition Research: A Critical Review", in Modern Language Journal, 80: 450-460.

Kodminsky, E. and Graetz, N. (1986). "First Versus Second Language Comprehension: Some evidence from Text Summarizing", in Journal of Research in Reading, 9, 1: 3-21.

Martínez, T., Vidal-Abarca, E., Sellés, P. and Gilabert, R. (2008). "Evaluación de las Estrategias y Procesos de Comprensión: El Test de Procesos de Comprensión", in Infancia y Aprendizaje, 31, 3: 319-332.

Morrison, L. (2004). "Comprehension Monitoring in First and Second Language Reading", in The Canadian Modern Language Review, 61, 1: 77-106.

Sánchez, E. (1993). Los Textos Expositivos. Estrategias para Mejorar su Comprensión. Madrid: Santillana. 
Sanjosé, V., Solaz, J.J and Gómez, A. (2011). "Control de la Comprensión Durante la Lectura de Textos de Ciencias en Inglés. ¿Están Preparados los Estudiantes Universitarios Españoles para Integrarse en el Espacio Europeo de Educación Superior?", in Didáctica de las Ciencias Experimentales y Sociales, 25: 149-163.

Segalowitz, N. (2000). "Automaticity and attentional skill in fluent performance", in H. Riggenbach (Ed). Perspectives on Fluency. Ann Arbor. MI: University of Michigan Press, 200-219.

Stanley, R.M. (1984). "The Recognition of Macrostructure: A Pilot Study", in Reading in a Foreign Language, 2: 156-168.

Thiede, K.W. and Anderson, M.C.M (2003). "Summarizing Can Improve Metacomprehension Accuracy", in Contemporary Educational Psychology, 28: 129-160.

Tsai, Y-R., Ernst, C. and Talley, P.C. (2010). "L1 and L2 Strategy Use in Reading Comprehension of Chinese EFL Readers", in Reading Psychology, 31, 1: 1-29.

Walczyk, J.J. (2000). "The Interplay Between Automatic and Control Processes in Reading”, in Reading Research Quarterly, 35: 554-566.

Walter, C. (2004). "Transfer of Reading Comprehension Skills to L2 is Linked to Mental Representations of Text and to L2 Working Memory", in Applied Linguistics, 25, 3: 315-339.

Walter, C. (2007). "First- to Second-Language Reading Comprehension: Not Transfer, but Access", in International Journal of Applied Linguistics, 17, 1: 14-37.

Winograd, P. and Johnston, P. (1982). "Comprehension Monitoring and the Error Detection Paradigm", in Journal of Reading Behavior, 14, 1: 61-76.

Yamashita, J. (2002). "Mutual Compensation Between L1 Reading Ability and L2 Language Proficiency in L2 Reading Comprehension", in Journal of Research in Reading, 25, 1: 81-95.

Zimmerman, B.J. (1990). "Self-Regulated Learning and Academic Achievement: An Overview", in Educational Psychologist, 25: 3-17. http://www.readabilityformulas.com/flesch-readingease-readability-formula.php), accessed September, 2011. 


\section{APPENDIX}

Text used in the Instructional sub-task 3.4. The embedded, inconsistent ideas have been underlined here.

\section{MAMMALS}

Mammals are the most widespread animals all over the world. They are also the most resistant to changeable environments and, together with insects, they are the most numerous of all the animals that live on the Earth. Thus, Mammals have adapted to environment successfully. They have survived under the most extreme conditions. We can find mammals in the desert, such as the camel; at the Pole, such as the polar bear; in the oceans, such as whales; underground, such as moles; or even at a height of 6,000 metres, such as yaks in Tibet.

There are several reasons which explain this success. The first cause lies in the fact that mammals take great care of their litters. The litters are under the protection of their parents until they can survive by themselves. Parents protect them from predators, they feed them and they instruct them. In this way mammals achieve the continuity of species.

Another explanatory factor lies in the special development of their brain, which allows them to learn from experience and, consequently, to adapt themselves to the environmental changes better than the rest of animals. Their brain is so complex that litters learn from experience without being taught by adults. The human being is a good example of this adaptation ability.

Finally, another reason of mammals' success is their ability to keep their internal body temperature constant. No matter what the outside temperature is, mammals' body temperature is constant, between $35^{\circ}$ and $39^{\circ}$. However, this fact makes them have problems to live in too hot or too cold habitats. Other kinds of animals, such as reptiles and amphibians, have adapted better than mammals in most extreme conditions. 